From the Schizophrenia and Psychopharmacology Joint Research Project

University of Michigan, Ann Arbor, Michigan and Ypsilanti State Hospital, Ypsilanti, Michigan

\title{
Use of the Cortical Epinephrine Pressor Response in Rabbits as a Diagnostic Test for Schizophrenia***
}

\author{
By \\ Shigeo Fudita and Norman Rosenzweig
}

(Received January 21, 1963)

\section{Introduction}

In 1953, Minz, Buser, and ALbe-Fessard observed that local application of concentrated epinephrine (5 to 10\%) to the rabbit's cortex could produce an elevation of blood pressure and this was further studied by MrNz and his colleagues in a series of papers (MrNz and Chamorro 1955; Minz and Chamorro 1956a, 1956b; Minz 1957; Chamorro and Minz 1957; Minz and Walaszer 1958a, 1958b; Minz and Sмттн 1958).

The pressor response normally can be elicited only from certain cortical areas; but repeated applications lead to sensitization so that previously ineffectual concentrations $(2 \%)$ become effective, and the responsive area gradually enlarges (MrNz and Chamorno 1956a; Minz and WALASZEK $1958 \mathrm{~b}$ ).

In 1957 Minz and WALASZEK reported that pretreatment of rabbits with serum from schizophrenics resulted, in $70 \%$ of the cases, in inhibition or inversion of the hypertensive response to cortically applied epinephrine, and to increased concentrations of catecholamines in the brain stem (Minz and WalaszeiK 1958a; Walaszeik, Minz and Sirtit 1958). Pretreatment with serum from normal subjects had none of these effects.

Because of the claimed differentiation between the sera of schizophrenic and non-schizophrenic subjects, these findings were reinvestigated with hospitalized patients, to assess the usefulness of this procedure as an adjunct to the diagnosis of schizophrenia.

\section{Materials and Methods}

Thirty subjects, selected from the population of the Ypsilanti State Hospital and matched, using the criteria of the Schizophrenia and Psychopharmacology Project (Gerard et al. 1963), were employed in

* Supported by United States Public Health Service grants MY.1971 and MY-1972, R. W. Gerard, M.D., Ph.D. Principal Investigator.

** With technical assistance of NeIr V. Williams. 
this study and seven members of the staff served as additional controls. Patients had been diagnosed independently by three psychiatrists and placed unanimously in a major diagnostic category of schizophrenic (15), non-schizophrenic (8), or uncertain (7). The fifteen schizophrenic subjects consisted of ten chronic undifferentiated, two hebephrenics, two catatonics, and one paranoid. The eight hospitalized non-schizophrenics consisted of six sociopaths (four with alcoholism), one chronic brain-syndrome with trauma and alcoholism, and one passive aggressive personality disorder. All subjects were males between 18 and 50 years old.

Blood was drawn from the anticubital vein of the subjects, allowed to clot for 90 minutes at room temperature, and then centrifuged for 10 minutes in a refrigerated centrifuge.

The experiments were carried out with albino rabbits of either sex, weighing between 2000 and $2400 \mathrm{~g}$. They were fed Rockland Rabbit Ration and water and were kept in a temperature-controlled animal room for several days before the experiments.

The amount and route of injections of serum to the rabbit and the time lapse before testing were varied in three different methods, selected on the basis of correspondence with Dr. WALASzEK.

Method A. $5 \mathrm{~cm}^{3}$ of serum were injected intravenously (i.v.) 16 to 20 hours before the test. This procedure was used by WALASZEK and in our preliminary experiments.

Method $B$. Two $5 \mathrm{~cm}^{3}$ samples of serum were injected intravenously, 24 hours apart, the second being administered 16 to 20 hours before the test. Fifteen rabbits so injected behaved as did those in $\mathrm{A}$.

$M$ ethod $C$. Two $2 \mathrm{~cm}^{3}$ samples of serum were injected subcutaneously (s.c.), 96 hours apart, the second being administered 16 to 20 hours before the test. This is the method most used by WALASzEK and presumably emphasizes pressor responses, but our results were not different from those with other methods.

In extensive exploratory work, only one or two rabbits died from i.v. injection of serum; but of 113 rabbits used in the study, 33 died after injection, before any surgical preparation was begun. Dr. WALASzeK informed us that other workers using the Minz test have also lost about a third of their rabbits after injection. In an effort to determine the cause, the $5 \mathrm{~cm}^{3}$ of serum were diluted to $10 \mathrm{~cm}^{3}$ with physiological saline, the rate of injection was set at about two minutes, syringes and centrifuge tubes were scrupulously cleaned, and special attention was given to the handling of the animals, which were petted and played with for several days before injection to minimize fright and shock. Mortality was not altered. Further, eight blanks were run by carrying saline through the full blood handling (centrifuging, transfer to test tube, warming to room temperature, injection into ear vein); all eight rabbits 
lived. Conversely, dialysis of serum did not lessen the rabbit mortality. Clearly, the serum itself was at times causing death; not the other factors checked. Whether the patients or the rabbits altered we cannot say; such shifts in findings over time are frequent and distressing happenings.

A $50 \%$ urethane solution, $1.0 \mathrm{~g} / \mathrm{kg} \quad$ i. p. or $1.2 \mathrm{~g} / \mathrm{kg} \quad$ s.c. (instead of $1.5 \mathrm{~g} / \mathrm{kg}$, MINz and Chamorno 1956), sufficed for anaesthesia. The craniotomy extended 5 to $7.7 \mathrm{~mm}$ both left and right from the sagittal suture (instead of only right, Minz and Chamorro 1956) and about $10 \mathrm{~mm}$. anterior from the coronal suture. Only the left meninges were then cut and laid back to expose the left cortex, avoiding damage to the sagittal sinus and brain. Blood pressure in the right femoral artery was measured in the usual way. The epinephrine solution used for the cortical application, following WALASZEK, was made up of $100 \mathrm{mg}$ epinephrine bitartrate in $1.8 \mathrm{~cm}^{3}$ Ringer's and $0.2 \mathrm{~cm}^{3}$ of a $10 \%$ sodium bicarbonate. It had a $\mathrm{pH}$ of 6.0 to 6.5 and, unlike the usual strongly acid solution (MTNz and CHAMorro 1956), did not damage the cortex. The area for topical applications (Mrnz's "fronto-parietal" area) was just anterior to the artery which usually runs 2 to $3 \mathrm{~mm}$ anterior to the vein at the coronal suture (the landmark for Procedure A) and close to the sagittal sinus. The artery was not always clearly defined and approximation was sometimes necessary; but a check indicated that precise placement was immaterial. A $3 \mathrm{~mm}$ square of filter paper, soaked in the test solution, was placed on the designated area for 30 seconds and five further applications were made at ten minute intervals (instead of 15, Mrnz and Chamorro 1956). Between applications, the cortex was covered with a cotton compress soaked in lukewarm physiological saline. After the six topical applications, a $4 \gamma / \mathrm{kg}$ epinephrine solution was injected into an ear vein, to check on the blood pressure response and the condition of the rabbit.

\section{Findings and Comments}

\section{Period 1 - Preliminary Experiments}

Twenty-six successful experiments on rabbits constituted an initial study. Animals which died on the board within two hours after exposure of the cortex, with the cortex in bad shape, with a blood pressure response to i.v. epinephrine (after 6 to 8 local applications) below $8 \mathrm{~mm} \mathrm{Hg}$, or with an initial blood pressure below $30 \mathrm{~mm} \mathrm{Hg}$ (usual range 50 to 80 ) were excluded. Brain damage during surgery led to inconsistent results; either all responses failed, or pressor responses were obtained from almost any point on the exposed surface, possibly from entry of epinephrine into the circulatory system. With low initial blood pressure, depressor responses were sometimes obtained when the skin was pinched 
or when the animal changed position. The cortex showed considerable functional deterioration by two hours after opening the dura (see also Kremer 1948 and Hofr 1937, 1936); therefore, only results of the first six to eight epinephrine applications were analyzed.

At the end of this period, Dr. WALASZEK kindly spent two days with us to check procedures and insure proper replication of the Minz test. He regards a series of pressor responses of $20 \mathrm{~mm} \mathrm{Hg}$ or higher as the norm for an untreated rabbit or one given serum from normal subjects, especially after sensitization to a series of topical applications. Onethird of the schizophrenic sera also fail to modify the "normal" pressor response to topical application of epinephrine (Mrnz 1957). Among the other two-thirds, three responses to epinephrine occur about equally: (1) a definite depressor response, sometimes appearing immediately but more often several minutes after the topical application; (2) a series of pressor responses, without sensitization, not exceeding $20 \mathrm{~mm} \mathrm{Hg}$ in height; and (3) no response at all.

If such criteria are applied to our recordings, schizophrenic patterns were obtained from sera from most of the patients, regardless of diagnoses (Table 1). We have, therefore, used three sets of criteria, including (1) that just described. In the second set (2), a series of pressor responses $10 \mathrm{~mm} \mathrm{Hg}$ to $20 \mathrm{~mm} \mathrm{Hg}$ in height, with sensitization, was taken as a non-schizophrenic response, other patterns as indicating schizophrenia. Finally (3), a series of pressor responses of any height, with sensitization, was taken as a non-schizophrenic response, other

Table 1

Period 1. Vasomotor responses to cortical application of epinephrine in rabbits

\begin{tabular}{|c|c|c|c|c|c|c|}
\hline \multirow{3}{*}{ Criteria* } & \multicolumn{2}{|c|}{ Control } & \multicolumn{2}{|c|}{$\begin{array}{l}\text { Treated with } \\
\text { schizophrenic serum }\end{array}$} & \multicolumn{2}{|c|}{$\begin{array}{c}\text { Treated with } \\
\text { non-schizophrenic serum }\end{array}$} \\
\hline & \multicolumn{2}{|c|}{ Pressor response ** } & \multicolumn{2}{|c|}{ Pressor response } & \multicolumn{2}{|c|}{ Pressor response } \\
\hline & Positive & Negative & Positive & Negative & Positive & Negative \\
\hline $20 \mathrm{~mm}$ or more & 2 & 6 & 1 & 15 & 1 & 1 \\
\hline $10 \mathrm{~mm}$ or more & 3 & 5 & 4 & 12 & 2 & 0 \\
\hline or sensitization & 4 & 4 & 5 & 11 & 2 & 0 \\
\hline Total & \multicolumn{2}{|c|}{8} & \multicolumn{2}{|c|}{16} & \multicolumn{2}{|c|}{2} \\
\hline
\end{tabular}

* $20 \mathrm{~mm}$ or more: indicates at least one pressor response $20 \mathrm{~mm} \mathrm{Hg}$ or more in height occurred in the first 6 to 8 applications. $10 \mathrm{~mm}$ or more: indicates at least one pressor response $10 \mathrm{~mm} \mathrm{Hg}$ or more in height occurred in the first 6 to 8 applications. $10 \mathrm{~mm}$ or sensitization: indicates either one pressor response $10 \mathrm{~mm}$ $\mathrm{Hg}$ or more in height, or at least 3 pressor responses in the first 8 applications show progressive increase in height even if no pressor response exceeds $8 \mathrm{~mm} \mathrm{Hg}$ in height.

** A positive pressor response is the normal or non-schizophrenic pattern, a negative one is reported to occur with sehizophrenic serum. 
patterns as indicating schizophrenia. Table 1 shows the results using these three criteria. Using the modified scales, our schizophrenic group is comparable to that of Dr. WALAszEk. Results on the control rabbits were inconsistent (Table 1). These were obtained during the winter season, when variability is reported to be greater (Mrnz and CHAMorro 1955; Minz 1958).

\section{Period 2-Pilot Study}

Procedures were modified along lines suggested by Dr. Walaszer (Method B) but even so control rabbits gave badly mixed responses, using any of the criteria (Table 2). At this time a group of patients on controlled diet and off drug therapy became available and their sera were tested, despite the inconsistency of control rabbits (Table 2). Onethird of these rabbits died simply from injection of serum.

Table 2. Period 2

\begin{tabular}{|c|c|c|c|c|c|c|}
\hline \multirow{2}{*}{ Criteria* } & \multicolumn{2}{|c|}{ Control } & \multicolumn{2}{|c|}{$\begin{array}{l}\text { Treated with } \\
\text { schizophrenic serum. }\end{array}$} & \multicolumn{2}{|c|}{$\begin{array}{c}\text { Treated with } \\
\text { non-schizophrenic serum }\end{array}$} \\
\hline & Positive & Negative & Positive & Negative & Positive & Negative \\
\hline $20 \mathrm{~mm}$ or more & 0 & 16 & 13 & 19 & 9 & 11 \\
\hline $\begin{array}{c}10 \mathrm{~mm} \text { or more } \\
10 \mathrm{~mm}\end{array}$ & 8 & 8 & 15 & 17 & 12 & 8 \\
\hline or sensitization & 10 & 6 & 18 & 14 & 13 & 7 \\
\hline Total & \multicolumn{2}{|c|}{16} & \multicolumn{2}{|c|}{32} & \multicolumn{2}{|c|}{20} \\
\hline
\end{tabular}

* See the footnote of Table 1.

The results for rabbits treated with sera from schizophrenic patients were similar to those obtained by MINz and WALAszer; about one-third (13 out of 32 ) showed pressor responses with sensitization; the others mostly gave no response at all or a very slight pressor response. A few rabbits gave definite depressor responses, which WALASZEK claims is unique to animals treated with schizophrenic serum.

Rabbits treated with sera from non-schizophrenic patients showed a pressor response in only about half the cases (9 out of 20). WALASZEK stated that a pressor response always is given by untreated rabbits or those treated with non-schizophrenic serum. Even if we regard any series of pressor responses, however small, with sensitization as being a non-schizophrenic pattern, only 13 of 20 responses could be so classified.

Table 4 shows that paired rabbits treated with serum from the same patient produced different results for 6 out of 10 sera. Also, and contrary to previous reports, rabbits responded differently to a given serum when administered subcutaneously (Method C) or intravenously (Method A). 


\section{Period 3 - Inconsistency of Control}

On completion of these patient tests, sera from eleven normal subjects (employees of the Project) were tested on 15 rabbits. These controls, run in May and June, 1959, like the earlier ones run in the winter, gave "schizophrenic" patterns half the time (Tables 1, 2, 3).

Only two of the 11 normal sera gave "non-schizophrenic" results (Table 3). Of the other 9, 7 gave low or absent pressor responses and 2 gave marked depressor responses, presumably characteristic of schizo-

Table 3. Period 3

\begin{tabular}{|c|c|c|c|c|}
\hline \multirow{2}{*}{ Criteria * } & \multicolumn{2}{|c|}{ Control } & \multicolumn{2}{|c|}{$\begin{array}{l}\text { Treated with } \\
\text { normal serum }\end{array}$} \\
\hline & Positive & Negative & Positive & Negative \\
\hline $20 \mathrm{~mm}$ or more & 7 & 8 & 0 & 11 \\
\hline $\begin{array}{l}10 \mathrm{~mm} \text { or more } \\
10 \mathrm{~mm} \text { or }\end{array}$ & 8 & 7 & 1 & 10 \\
\hline sensitization & 8 & 7 & 2 & 9 \\
\hline Total & \multicolumn{2}{|c|}{15} & \multicolumn{2}{|c|}{11} \\
\hline
\end{tabular}

phrenia. Moreover, as above, different rabbits treated with a given serum reacted differently.
Period 4-Modification of the Test

A. When serum was injected into rabbits "acutely" - after completion of surgery rather than a day earlier -

the pressor responses to epinephrine were enhanced, both for schizophrenic and non-schizophrenic sera. The enhancement, occasionally considerable, might have been due in part to continued exposure of the cortex, for similar increases were also observed in control rabbits.

B. Since many patients had earlier been on drugs, several of these were explored. Chlorpromazine $(5 \mathrm{mg} / \mathrm{kg}$ injected i.m. $20 \mathrm{~min}$ before the test) seemed to prevent pressor responses, but iproniazid (100 $\mathrm{mg} / \mathrm{kg}$ i. v., 4 hours before the test) did not. Reserpine $(0.75 \mathrm{mg} / \mathrm{kg}$ i.m., 4 hours before the test) increased the sensitivity to topically applied epinephrine; rabbits so pre-treated showed pressor responses and sensitization to topically applied epinephrine in every case. Earlier injection of schizophrenie sera did not prevent this reserpine action. Serum-treated rabbits which showed no response to the first six applications of topical epinephrine gave pressor responses one hour after being injected with reserpine. Since results with untreated rabbits were so inconsistent, we decided to use reserpine sensitization in testing the differences in sera from non-schizophrenics and schizophrenies. With neither Method A nor $\mathrm{C}$ were clear differences demonstrable. The drug effects were sufficiently minor, even with these doses, to exclude these as a factor in our clinical test results.

The total outcome, of more than a year's work on hundreds of rabbits, did not justify further effort, and exploration of the Minz test was abandoned. 


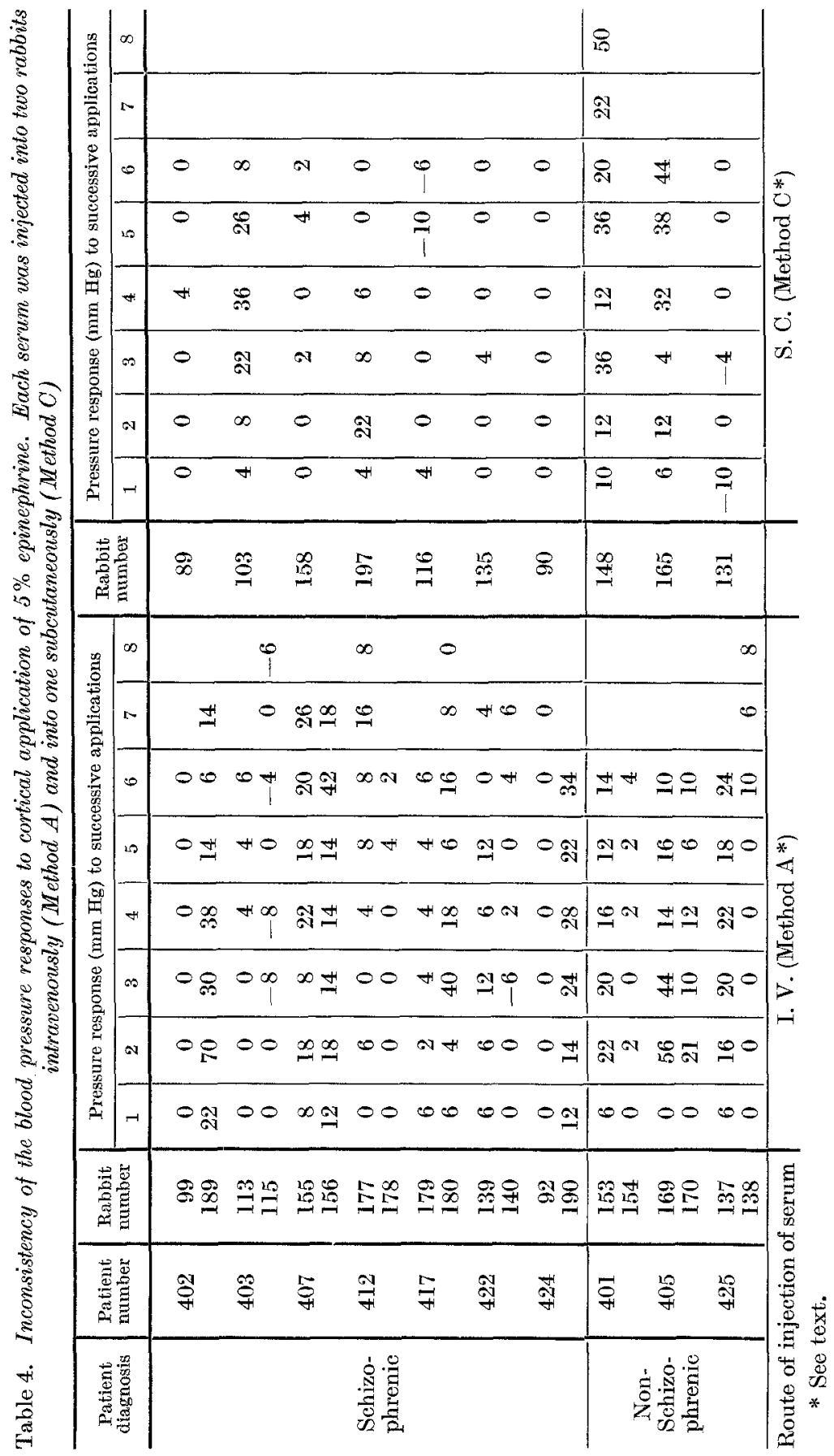




\section{Discussion}

Our results do not support the claim of MINz and WALAszeK that schizophrenic sera act differently from non-schizophrenic sera on the blood pressure responses induced by local application of epinephrine to the rabbit cortex. Responses were highly variable, even if different animals were given the same serum, and the variance was similar for control animals and those injected with either type of serum. No modification of injection or testing procedures led to improvement. Dr. WALASZEK, reporting also for MINZ, agreed in 1958 that "the cortical epinephrine pressor response is not a diagnostic test".

Some positive findings have, nonetheless, emerged: (1) human serum contains one or more substances toxic to rabbits; (2) topical application of epinephrine $(5 \%)$ to the cerebral cortex can cause an elevation of blood pressure in about half the normal rabbits tested; and (3) in a few experiments with reserpine, all animals reacted with pressor responses.

Toxic substances in human serum. The literature reports that human serum contains toxic substances which affect most mammals tested. BALDI (1926) found that rabbits showed toxic reactions if injected i.v. with 8 to $10 \mathrm{~cm}^{3}$ of serum per kilo body weight from normal subjects and paranoid schizophrenies, with 6 to $7 \mathrm{~cm}^{3}$ from hebephrenics, or with 3 to $5 \mathrm{~cm}^{3}$ from catatonics. SJövaLL (1947) also reported that by 24 hours after intravenous injection of normal human serum half the mice had died ( $14.7 \pm 1.8$ of 30$)$. In our experiments, 33 out of 113 rabbits treated with $5 \mathrm{~cm}^{3}$ of serum died. Sera of 11 of 15 schizophrenics caused death (24 of 65 injected rabbits), while only 5 of 15 non-schizophrenic sera caused death ( 9 of 48 injected rabbits). The differences are at least suggestive, especially in view of many other reports of toxic substances in schizophrenic body fluids.

A cortical component in vasomotor regulation. In 1886, STRICKER postulated vasomotor centers within the cerebral cortex because faradic stimulation of the frontal lobes caused strong elevation of systolic blood pressure in curarized animals. In 1899, HoweLL and Austis reported for dogs under morphine and ether that a fall of blood pressure generally followed stimulation of the sigmoid area; but for dogs under morphine and curare a rise was usual.

In 1948, KREMER obtained good depressor responses by local application of a $2.5 \%$ mecholyl solution to the motor cortex and to the anterior ectosylvian gyrus of dogs under Dial or sodiumamytal anesthesia, but obtained no vasomotor response with epinephrine. In general, cardiovascular areas are located in the anterior cortex, but with no systematic distribution of pressor and depressor areas (DELGADo 1960; GREEN and HoFF 1937). As is the case for cortical motor centers, where "the kind of response to excitation is never predictable; the same point may at 
one moment give flexion and at another extension" (LovaTT-Evans 1956), so for cortical pressor and depressor points. Withoutcareful control of kind and depth of anesthesia the cardiovascular reactions to cortical stimulation vary widely (DELGADO 1960; HoFF and GREen 1936).

The effect of reserpine on the cortical vasomotor response is complicated by the fact that reserpine also increases the response to injected epinephrine (HARRISON and GoTH 1956). In our experiments, rabbits were drowsy 20 hours after reserpine, did not seem frightened by handling, and showed low blood pressure $(50-60 \mathrm{~mm} \mathrm{Hg})$ just after the cortex was exposed (urethane 1.0 per kilo, s.c.). These reserpine findings deserve further study.

\section{Summary}

1. A careful replication of the Minz and Walaszek test failed to demonstrate its reliability as a clinical tool for diagnosing schizophrenia.

2. Human serum contains substances toxic to rabbits. There is some indication that schizophrenic serum has greater toxicity than nonschizophrenic sera.

3. Local application of a $5 \%$ epinephrine solution to the cerebral cortex causes a rise in blood pressure in about half the rabbits treated with normal serum.

4. Effects of some tests with psychoactive drugs on the local epinephrine responses are reported.

Acknowledgments. The authors wish to express their thanks to Drs. RaLPH Gerard, Alexander Dukay, Steven Vandenberg, Edward Domino, Arthur YuWHer, and StePhen Fox for interest and valuable advice; to Drs. GERARD and YUWILER and Mrs. LUCY WATKINS for help in preparation of the manuscript; to Mr. James O'Brien and Mr. Neil Williams for able technical assistance; and to ward personnel for many sorts of aid. Dr. FuJITA is grateful to Dr. Hrdezo NAKAGAWA for permission to remain for a long and profitable time in the United States.

\section{References}

BALDI, F.: Ricerche sperimentali sul sangue dei dementi precoci. I. Neurologica (Napoli) 3, 91-111 (1926).

Chamorro, A., et B. Minz: Localisation d'une activité ocytocique dans l'hypothalamus postérieur du lapin. C.R. Soc. Biol. (Paris) 151, 496-499 (1957).

Delgado, José M. R.: Circulatory effects of cortical stimulation. Physiol. Rev. 40, Suppl. No 4, 146-171 (1960).

Gerarn, R. W.: The nosology of schizophrenia. Amer. J. Psychiat. 1963 (in press).

Green, H. D., and E. C. HoFf: Effects of faradic stimulation of the cerebral cortex on limb and renal volumes in the cat and monkey. Amer. J. Physiol. $118,641-658$ (1937).

HARRISON, F., and A. GoTH: Effect of reserpine on the hypothalamic pressor response. J. Pharmacol. exp. Ther. 116, 262-267 (1956).

HofF, E. C., and H. D. Grews: Cardiovascular reactions induced by electrical stimulation of the cerebral cortex. Amer. J. Physiol. 117, 411-422 (1936). 
HoweLL, W. H., and M. F. AustrN : The effect of stimulation of various portions of the cortex cerebri, caudata nucleus, and dura mater upon blood pressure. Amer. J. Physiol. 3, 22-23 (1899).

KeTY, S. S.: Biochemical theories of schizophrenia. Part II of a two part critical review of current theories and of the evidence used to support them. Science $129,1590-1596(1959)$.

Kremer, W. F.: Blood pressure changes in response to electrical and chemical (Acetyl- $\beta$-methylcholine) stimulation of the cerebral cortex in dogs. Amer. J. Physiol. 152, 314 -323 (1948).

Lovatr-Evans, C.: Starling's principles of human physiology. Philadelphia: Lea and Febiger 1956.

Mrvz, B.: Actions de drogues tranquillisantes sur la réaction du cortex cérébral à l'adrenaline. C.R. Soc. Biol. (Paris) 151, 432-436 (1957).

- P. Buser et D. Albe-Fessard : Effet presseur de l'adrenaline appliquée localement sur le cortex du lapin. C.R. Soc. Biol. (Paris) 147, 1154-1156 (1953).

-, et A. Chayrorro: Sur une action corticohypothalamique déclenchée par l'adrenaline. C.R. Acad. Sci. (Paris) 240, $454-455$ (1955).

- Sensibilisation à distance par l'adrenaline appliquee sur le cortex cerebral du lapin. C.R. Soc. Biol. (Paris) 150, 299-303 (1956a).

- - Diffèrenciation pharmacodynamique d'effets corticaux et périphériques de l'adrenaline. C.R. Soc. Biol. (Paris) 150, 849-853 (1956 b).

-, et E. J. WataszeK: Sur le mécanisme de l'inhibition de la réaction corticale à l'adrenaline chez des lapins traités avec du sérum de schizophrénes. C.R. Acad. Sci. (Paris) 246, 1326-1328 (1958a).

- - Tropic action of epinephrine on the cerebral cortex of rabbits pretreated with serum from schizophrenics. J. Pharmacol. exp. Ther. 122, $53 \mathrm{~A}$ (1958b).

Srövall, T.: Preliminary studies on a possible serum toxicity in schizophrenia. Acta psychiat. scand., Suppl. 47, 105-117 (1947).

Stricker, S.: Untersuchungen über die Gefäßnervenzentren im Gehim und Rückenmark. Med. Jb. 1, 1-19 (1886).

Trapold, J. H., A. T. Plummer and F. F. Yonkman: Cardiovascular and respiratory effects of serpasil, a new crystallin alkaloid from rauwolfia serpentina benth., in the dog. J. Pharmacol. exp. Ther. 110, 205-214 (1954).

WALASZEK, E. J.: Personal communication 1959.

-, and B. Mrnz: Neurohormonal changes in brains of rabbits pretreated with serum from schizophrenics. J. Pharmacol. exp. Ther. 122, $80 \mathrm{~A}$ (1958).

- _ and C. M. SмiтH: Effects of serum from schizophrenic patients on neurohumors in rabbit brain. Fed. Proc. 17, No 1, 1645 (1958).

Shigeo FuJITa, M.D., Ph.D., Department of Neuropsychiatry, Sapporo Medical School, Sapporo, Japan

Norman Rosenzweig, M.D., Department of Psychiatry, Sinai Hospital of Detroit, Michigan 